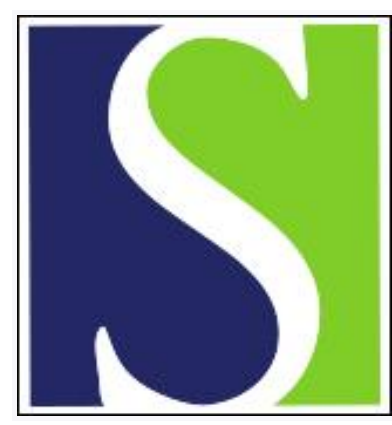

Scand J Work Environ Health 1994;20(6):401-406

https://doi.org/10.5271/sjweh.1381

Issue date: 01 Dec 1994

Nocturnal eating and serum cholesterol of three-shift workers.

by Lennernas M, Ákerstedt T, Hambraeus L

Affiliation: Department of Nutrition, University of Uppsala, Sweden.

The following articles refer to this text: 2010;36(2):150-162;

2019;45(1):7-21

This article in PubMed: www.ncbi.nlm.nih.gov/pubmed/7701285

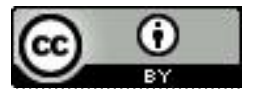




\title{
Nocturnal eating and serum cholesterol of three-shift workers
}

\author{
by Maria Lennernäs, DrMedSci, ${ }^{1,2}$ Torbjörn Åkerstedt, PhD, ${ }^{2}$ Leif Hambræus, MD ${ }^{1}$
}

LENNERNÄS M, ̊̊KERSTEDT T, HAMBRÆUS L. Nocturnal eating and serum cholesterol of threeshift workers. Scand J Work Environ Health 1994;20:401-6.

\begin{abstract}
Oвjectives - The goal of this study was to examine the effect of rotating three-shift work on the circadian distribution of dietary intake and to investigate the relationships between displaced eating and nutritional status variables [blood lipids, blood glucose, body mass index (BMI)].

Methods - Dietary data were collected by 147 replicate 24-h dietary recalls from 22 male industrial workers in rotating three-shift work. The intakes of energy and nutrients were estimated by the use of a nutrient data base. The BMI was calculated, and blood glucose, serum triglycerides, high-density lipoprotein (HDL) cholesterol and low-density lipoprotein (LDL) cholesterol were measured once.

Results - The dietary intakes of energy, protein, total fat, saturated fat, total carbohydrates, sucrose, and dietary fiber did not differ between 24 -h periods but did differ between work shifts and were lowest during the night. Correlation analyses between dietary intakes and nutritional status parameters showed that those who redistributed their eating most to the night shift had higher levels of serum total choIesterol and LDL and a higher LDL:HDL ratio; 63\% of the LDL cholesterol level was explained by carbohydrate intake during night shifts. In contrast, the total intake for whole 24-h periods or across entire shift cycles was not related to serum variables or BMI.

Conclusions - Dietary intake is lower during night shifts $(34-37 \%$ of 24 -h intake of various nutrients) than during morning shifts $(43-47 \%)$ and afternoon shifts $(47-59 \%)$. The redistribution of food intake to the night may be associated with metabolic disturbances in lipid metabolism.
\end{abstract}

KEY TERMS - body mass index, chronobiology, displaced eating, food intake, meal order, nutrients, nutrition survey, population nutrition, serum lipids, triglycerides.

Night work has been demonstrated to be responsible for an elevated risk of ischemic heart disease (1). This finding might be related to eating habits $(2,3)$. Night shift work causes a sizeable, temporal redistribution of meal taking from day to night (4). This nightly food intake will coincide with the circadian nadir of most physiological functions $(5,6)$. Furthermore, laboratory data show that food intake during the circadian nadir may induce abnormal metabolic behavior $(2,3,7)$. Thus one might expect frequent night eating to be related to undesirable metabolic effects, for example, increased levels of serum lipids or an increased body mass index (BMI).

The aim of the present study was to relate interindividual differences in the temporal distribution of food intake during different work shifts to the levels of plasma lipids, blood glucose, and BMI.

1 Department of Nutrition, University of Uppsala, Uppsala, Sweden.

2 The National Institute for Psychosocial Factors and Health and the Department of Stress Research, Karolinska Institute, Stockholm, Sweden.

Reprint requests to: Dr M Lennernäs, National Food Administration, Nutrition Division, S-751 26 Uppsala, Sweden.

\section{Subjects and methods}

Of the 45 (male) three-shift workers, 25-55 years old, who were asked to participate, six were excluded (two due to refusal, four for other reasons). All of the participants were Swedish citizens who had at least one year of experience with the present workhours. Dietary data were collected from 34 (morning and afternoon shifts), 37 (days off), and 38 subjects (night shifts). Blood samples were collected from 34 subjects. However, only data from the final sample of 22 subjects having complete dietary data (all shifts and days off observed) and data on blood lipids could be used in this study.

The mean age was 35.7 (SD 7.2) years. The subjects were 1.80 (SD 0.04) $\mathrm{m}$ tall and weighed 79 (SD 7) kg. Their BMI was 24.5 (SD 1.9), and the following serum levels were observed: 1.6 (SD 1.0) $\mathrm{mmol} \cdot \mathrm{l}^{-1}$ for triglycerides, 5.6 (SD 1.1$) \mathrm{mmol} \cdot \mathrm{l}^{\prime}$ for total cholesterol, 1.2 (SD 0.2) $\mathrm{mmol} \cdot 1^{-1}$ for HDL cholesterol, 3.7 (SD 1.1) $\mathrm{mmol} \cdot \mathrm{l}^{-1}$ for LDL cholesterol, 3.2 (SD 1.9) $\mathrm{mmol} \cdot \mathrm{l}^{-1}$ for LDL:HDL ratio, and 5.2 (SD 0.3) $\mathrm{mmol} \cdot \mathrm{l}^{-1}$ for blood glucose. Sixty-eight percent of the subjects used tobacco (snuff included), $68 \%$ ( 15 subjects) reported low physical activity during work, $61 \%$ (13 subjects) reported low physical activity during leisure time.

The study was carried out at two factories located close to each other in the rural area in the county of 
Uppsala, Sweden. One factory manufactured cutting tools and cemented carbide products, and the other manufactured insulating material. The two worksites used the same health care unit and the same canteen. The worktasks involved monitoring, truck driving, assembling, and both lifting and carrying. The morning, afternoon, and night work shifts ( $36 \mathrm{~h}$ a week) took place between 0530 and 1400 (meal break 0930 to 1000 ), 1400 and 2230 (meal break 1830 to 1900), and 2230 and 0530 , respectively. There were no fixed-meal breaks during the night shifts, but most of the men had their meal in the interval 0100 to 0200. The three-shift work schedule rotated slowly forwards, each work cycle comprising three weeks - one week including five morning shifts, one week including five afternoon shifts, and one week including four night shifts. The night shift week started on Monday evening and ended on Friday morning. Weekends were free.

Dietary data. A standardized 24-h dietary recall method (8) was used. Altogether 147 repeated interviews were carried out in the group to reflect the food consumption for the same individual across a work cycle, including all types of workshifts and days off. To get more reliable data on the usual intake of each individual for a particular shift day, repeated interviews were done, and mean values for each particular shift day and subject were used for further calculations. The interviews took place at the worksite during workhours and by telephone during days off. The subjects were asked to report their consumption from midnight to midnight the previous day. Fresh food items of different kinds and sizes, together with plates and glasses, were available as references for estimating consumed amounts. Volumes were converted to weight by density factors (9). Dietary data were entered (food item per dish, consumed weight and time of day for consumption) into a nutrient calculation system including the Swedish nutrient data base, which is based on Swedish Food Composition Tables (10).

The intakes of energy, protein, total fat, saturated fat, total carbohydrates, sucrose, and dietary fiber (weight units) were calculated. Total carbohydrates comprised mono-, di- and oligosaccharides, starch, and dietary fiber. Dietary fiber comprised plant cell contents (water soluble + water insoluble polysaccharides) and crude fiber (cellulose + lignin). Total fat comprised triglycerides (glycerol + saturated, monounsaturated, and polyunsaturated fatty acids), phospholipids, and sterols (including dietary cholesterol).

For each individual, the intakes of energy and nutrients were estimated with regard to the following three different time periods: (i) the intake during different 24-h days including morning, afternoon, and night shifts, (ii) the average daily intake on the basis of observations from different $24-\mathrm{h}$ workshift days and days off (representing a full work cycle) (11), and (iii) the intakes during work shifts (morning, afternoon, and night shifts). The latter values were transformed into a relative value $=$ percentage of 24-h intake for each actual workshift day. Night work shifts comprised $8 \mathrm{~h}$ (break included), and morning and afternoon work shifts comprised $8.5 \mathrm{~h}$ (30-min break included). Night shift intake included consumption from the period from midnight to 0530 and for the period from 2230 to midnight (the end of one night shift together with the beginning of the next night shift) during the same day.

Nutritional assessment. Anthropometric measures (weight and height) and blood sampling were performed by the health care unit. BMI was calculated as BMI = weight $(\mathrm{kg}) \cdot \mathrm{m}^{-2}(8)$. Blood was collected between 0600 and 0800 , at the beginning of the workday (morning shifts) after a 10-h overnight fasting. (No samples were taken during the afternoon or night shift weeks.) The samples were analyzed with a Greiner G 300 autoanalyzer (for blood glucose, serum triglycerides, and total, HDL and LDL cholesterol) at the Uppsala University Hospital, the Department of Clinical Biochemistry.

The subjects were also asked about their use of tobacco (snuff included) and about their daily physical activity during work and leisure time (the latter scored as $1=$ very low, $2=$ low, $3=$ rather high, 4 = high).

Statistical methods. The variation in dietary variables between 24-h periods and 8-h workshifts were analyzed through a one-factor analysis of variance for repeated measures. To correct for sphericity, the epsilon correction of Greenhouse-Geisser (G-G E) was applied to the degrees of freedom. In the results the original degrees of freedom are given together with the adjusted $P$-value. For a significant $F$ ratio pairwise comparisons were also made (Scheffé) (12). Each of the nutritional status variables was correlated to age, use of tobacco, daily physical activity, and dietary variables by simple, two-tailed correlation analyses (Pearson's product-moment correlation) and multiple regression analyses (13).

Software (Macintosh) from Abacus Concepts Inc [StatView II ${ }^{\mathrm{TM}}$ version 1.03 (1988) \& SuperANOVA version 1.01 (1989)] were used for the statistical calculations. For the dietary calculations, the MATs nutrient calculation system, including the Swedish nutrient data base, was used (14).

\section{Results}

The average daily intake (mean across all shifts and days off) and the 24-h intake during the night shift day are indicated in table 1 . (The 24-h intakes during the morning and afternoon shifts are not shown.) 
Table 1. Results from the repeated measures analysis of variance of relative (percentage of $24 \mathrm{~h}$ ) food intake across shifts. The mean and standard deviation are also given for the intake across one work cycle and for the 24-h intake during the night shift "day" (degrees of freedom $=2 / 42$ ).

\begin{tabular}{|c|c|c|c|c|c|c|c|c|c|c|c|}
\hline \multirow{3}{*}{ Nutrients } & \multirow{2}{*}{\multicolumn{2}{|c|}{$\begin{array}{l}\text { 24-h intake } \\
\text { across work } \\
\text { cycle }\end{array}$}} & \multirow{2}{*}{\multicolumn{2}{|c|}{$\begin{array}{l}\text { 24-h intake } \\
\text { night shift } \\
\text { "day" }\end{array}$}} & \multicolumn{7}{|c|}{ Comparison of $\%$ of $24-\mathrm{h}$ intake during a workshift } \\
\hline & & & & & \multicolumn{2}{|c|}{$\begin{array}{c}\text { Morning } \\
\text { shift }\end{array}$} & \multicolumn{2}{|c|}{$\begin{array}{l}\text { Afternoon } \\
\text { shift }\end{array}$} & \multicolumn{2}{|c|}{$\begin{array}{l}\text { Night } \\
\text { shift }\end{array}$} & \multirow{2}{*}{$\begin{array}{l}\text { F-ratio, } \\
\text { levels of } \\
\text { signifi- } \\
\text { cance }^{a}\end{array}$} \\
\hline & Mean & SD & Mean & SD & $\%$ & SD & $\%$ & SD & $\%$ & SD & \\
\hline $\begin{array}{l}\text { Energy }(\mathrm{MJ}) \\
\text { Protein }(\mathrm{g}) \\
\text { Total carbohydrates }(\mathrm{g}) \\
\text { Sucrose }(\mathrm{g}) \\
\text { Dietary fiber }(\mathrm{g}) \\
\text { Total fat }(\mathrm{g}) \\
\text { Saturated fat }(\mathrm{g})\end{array}$ & $\begin{array}{c}12.0 \\
104 \\
326 \\
61 \\
22 \\
120 \\
55\end{array}$ & $\begin{array}{l}3.3 \\
25 \\
91 \\
29 \\
10 \\
35 \\
17\end{array}$ & $\begin{array}{r}12.8 \\
111 \\
364 \\
64 \\
25 \\
128 \\
59\end{array}$ & $\begin{array}{l}3.7 \\
31 \\
128 \\
42 \\
13 \\
36 \\
19\end{array}$ & $\begin{array}{l}47 \\
47 \\
47 \\
43 \\
46 \\
46 \\
46\end{array}$ & $\begin{array}{l}17 \\
16 \\
14 \\
25 \\
20 \\
21 \\
21\end{array}$ & $\begin{array}{l}51 \\
48 \\
53 \\
59 \\
52 \\
48 \\
47\end{array}$ & $\begin{array}{l}16 \\
18 \\
16 \\
24 \\
21 \\
18 \\
19\end{array}$ & $\begin{array}{l}35 \\
35 \\
35 \\
35 \\
34 \\
35 \\
37\end{array}$ & $\begin{array}{l}10^{\mathrm{b}} \\
10^{\mathrm{b}} \\
11^{\mathrm{b}} \\
18^{\mathrm{c}} \\
16^{\mathrm{b}} \\
13^{\mathrm{b}} \\
13^{\mathrm{b}}\end{array}$ & $\begin{array}{c}11.20^{\star * *} \\
7.83^{* * *} \\
14.42^{\star \star \star *} \\
8.02^{* *} \\
9.54^{* \star \star} \\
5.98^{\star *} \\
4.23^{*}\end{array}$ \\
\hline
\end{tabular}

a The degrees of freedom were adjusted for sphericity by the G-G coefficient, levels of significance for adjusted P-values: ${ }^{\star} P<0.05 ;{ }^{*} \mathrm{P}<0.01 ;{ }^{* \star *} \mathrm{P}<0.001$.

b For significant $P$-values, also results from pairwise comparisons (Scheffé): significantly different from morning and afternoon.

c For significant P-values, also results from pairwise comparisons (Scheffé): significantly different from afternoon.

Table 2. Relationship between dietary variables and serum cholesterol according to results from simple regressions. Only significant results reported ${ }^{2}$ (two-tailed tests) $(N=22$ male shift workers, degrees of freedom $=20$ ). (HDL $=$ high-density lipoprotein, $\mathrm{LDL}=$ low-density lipoprotein)

\begin{tabular}{|c|c|c|c|c|}
\hline & $\begin{array}{c}\text { Total } \\
\text { cholesterol } \\
5.6(\mathrm{SD} 1.1) \mathrm{mmol} \\
(r) \\
\end{array}$ & $\begin{array}{c}\text { HDL } \\
\text { cholesterol } \\
1.2(\mathrm{SD} 0.2) \mathrm{mmol} \\
(r) \\
\end{array}$ & $\begin{array}{c}\text { LDL } \\
\text { cholesterol } \\
3.7 \text { (SD 1.1) } \mathrm{mmol} \\
(\mathrm{r})\end{array}$ & $\begin{array}{c}\text { LDL : HDL } \\
\text { ratio } \\
3.2 \text { (SD 1.2) } \mathrm{mmol} \\
\text { (r) }\end{array}$ \\
\hline \multicolumn{5}{|c|}{ Average 24-intake (amounts) } \\
\hline Dietary fiber & . & $\cdot$ & $0.483^{\star}$ & $0.506^{\star}$ \\
\hline \multicolumn{5}{|c|}{ Relative morning shift $(\%)$} \\
\hline $\begin{array}{l}\text { Energy } \\
\text { Total fat } \\
\text { Saturated fat } \\
\text { Total carbohydrates } \\
\text { Dietary fiber }\end{array}$ & $\dot{.}$ & $\begin{array}{l}-0.463^{*} \\
. \\
-0.430^{*} \\
-0.463^{*} \\
-0.560^{* *}\end{array}$ & : & $\dot{i}$ \\
\hline \multicolumn{5}{|l|}{ Relative night shift (\%) } \\
\hline $\begin{array}{l}\text { Energy } \\
\text { Protein } \\
\text { Total fat } \\
\text { Saturated fat } \\
\text { Total carbohydrates } \\
\text { Dietary fiber }\end{array}$ & $\begin{array}{l}0.701^{\star \star} \\
0.689^{\star *} \\
0.525^{\star} \\
0.494^{\star} \\
0.758^{\star *} \\
0.646^{\star *}\end{array}$ & $\begin{array}{c}\dot{.} \\
\dot{.} \\
-0.437^{*}\end{array}$ & $\begin{array}{l}0.732^{\star *} \\
0.681^{* *} \\
0.548^{\star *} \\
0.506^{\star} \\
0.796^{\star *} \\
0.747^{\star *}\end{array}$ & $\begin{array}{l}0.681^{* *} \\
0.617^{* *} \\
0.497^{*} \\
0.451^{*} \\
0.751^{* *} \\
0.769^{* *}\end{array}$ \\
\hline
\end{tabular}

a Independent dietary variables tested: energy, protein, total fat, saturated fat, total carbohydrates, sucrose, and dietary fiber. The dietary intake measured as the average daily intake in a person across one work cycle and as relative $(\%)$ to $24-h$ intake during workshifts. Other independent variables tested: age, use of tobacco, physical activity during work, and physical activity during leisure time. Dependent variables tested: serum triglycerides, serum total cholesterol, serum HDL and LDL cholesterol, the LDL: HDL ratio, blood-glucose, and body mass index.

The 24-h intakes of energy and nutrients were compared through a repeated measures analysis of variance. No significant differences were found between workshift days. The food intake during the workhours of a particular shift was then expressed as the percentage of the intake during the entire $24-\mathrm{h}$ period containing the shift. The relative values for the shifts (percentage of 24-h intake of energy and nutrients during workshifts) were then compared through a repeated-measures analysis of variance. This analysis showed a significant variation across the workshifts for the relative intake of energy and all nutrients. There were no differences between the morning and afternoon shifts, but the relative intakes of energy and all nutrients during the night shift were significantly reduced. Between 40 to $50 \%$ of the 24-h intakes was consumed during the morning and afternoon shifts. The consumption during the night shifts ranged between 30 and $40 \%$.

Each of the variables blood glucose, triglycerides, serum total cholesterol, serum HDL cholesterol, serum LDL cholesterol, the HDL:LDL ratio, and BMI were then correlated with each of the variables age, use of tobacco, physical activity during leisure time, physical activity during work, average daily intake across one work cycle, and relative workshift consumption (percentage of 24-h intake).

Table 2 shows that the relative night shift consumption correlated significantly with (increased) LDL cholesterol and that the relative morning shift consumption correlated significantly with (decreased) HDL cholesterol. No significant correlations were 


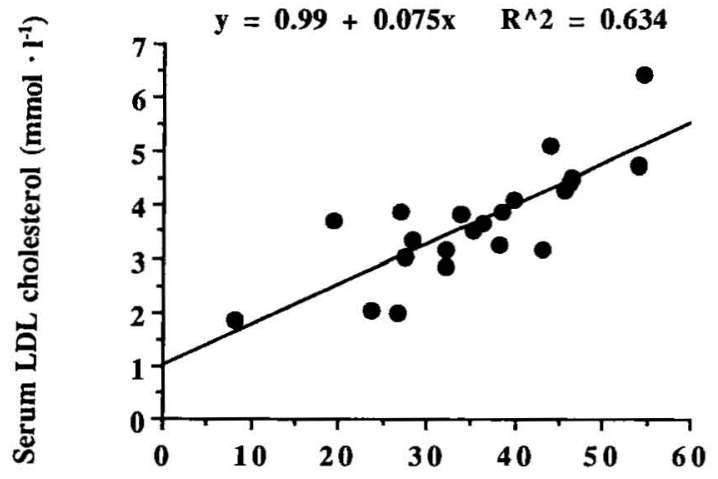

Carbohydrates \% 24-h intake night shift

Figure 1. Correlation between relative intake (percentage of $24 \mathrm{~h}$ ) of carbohydrates during night workshifts and serum low-density lipoprotein (LDL) cholesterol $(\mathrm{N}=22$ male shift workers).

Table 3. Relation between average daily $24-\mathrm{h}$ intake and relative workshift intake, respectively, and serum LDL cholesterol. Results from multiple regressions controlled for age, and from simple two-tailed regressions ( $\mathrm{N}=22$ male shift workers). (LDL = low-density lipoprotein, NS = not significant)

\begin{tabular}{|c|c|c|c|c|}
\hline & \multicolumn{4}{|c|}{ Multiple regression } \\
\hline & R 2 & $\beta$ & $F$ & df \\
\hline \multicolumn{5}{|l|}{ Step 1} \\
\hline Age & 0.140 & 0.369 & 3.15 & $1 / 20$ (NS) \\
\hline \multicolumn{5}{|l|}{ Step 2} \\
\hline \multirow{3}{*}{$\begin{array}{l}\text { Age } \\
\text { Percentage of 24-h } \\
\text { energy night shift }\end{array}$} & & 0.205 & & \\
\hline & 0.580 & 0.683 & 12.09 & $2 / 19(P<0.01)$ \\
\hline & \multicolumn{4}{|c|}{ Simple regression } \\
\hline Energy intake & $r$ & & & \\
\hline $\begin{array}{l}\text { Average daily } 24-h \\
\text { intake }\end{array}$ & -0.089 & & & \\
\hline $\begin{array}{l}\text { Percentage of 24-h } \\
\text { intake morning shift }\end{array}$ & 0.258 & & & \\
\hline $\begin{array}{l}\text { Percentage of 24-h } \\
\text { intake afternoon shift }\end{array}$ & 0.124 & & & \\
\hline $\begin{array}{l}\text { Percentage of 24-h } \\
\text { intake night shift }\end{array}$ & $0.732^{\star \star *}$ & & & \\
\hline Age (forced) & 0.369 & & & \\
\hline
\end{tabular}

found for the afternoon shifts. For the average diet, only dietary fiber correlated significantly with (increased) LDL cholesterol. No significant correlations were found for age, use of tobacco, physical activity during work, physical activity during leisure time, or sucrose or for serum triglycerides, blood glucose, or BMI. Figure 1 illustrates the regression between the relative night shift values for total carbohydrates and serum LDL cholesterol.

In order to control for age and to evaluate more directly the role of the relative intake during worktime, a multiple regression analysis against LDL cholesterol was carried out (table 3). Since the intakes of all nutrients and energy were highly intercorrelated, energy was selected as the most representative of the dietary variables. Age (forced) and relative workhour values for each shift, as well as total absolute intake (across all three 24-h periods with shifts and days off), were used as the predictors. LDL cholesterol was explained by age (14\%) and relative energy intake during the night shift (44\%) together.

\section{Discussion}

The main impression of the present study is that rotating three-shift work affects the circadian distribution of energy intake but not the 24-h intake per se. However, the results indicate that a redistribution of eating from afternoon to night might be associated with increased levels of serum total cholesterol and LDL cholesterol. Furthermore, the results indicate that a redistribution of eating from afternoon to early morning might be associated with decreased levels of HDL cholesterol. The subjects who ate similar amounts during workshifts regardless of the time of day had higher levels of serum LDL cholesterol (much eating during the night shift) and also lower levels of serum HDL cholesterol (much eating during the morning shift). Thus eating at noon and during the afternoon seems preferable. Since age was controlled for and since the total intake was not related to the nondietary variables tested (use of tobacco, physical activity during work, and physical activity during leisure time), it appears that the key factor is the change from diurnal to nocturnal eating rather than other possible factors related to blood lipids.

Before the possible mechanisms are discussed, it should be emphasized that the blood samples were not collected in connection with night work. Thus the results should not be an artefact of the timing of the blood sampling. The sample size was admittedly small, but the bivariate distributions were acceptably normal (see figure 1), and the sample seemed representative of three-shift workers in general (11). Neither does there seem to be any reason to suspect that the results were biased by the method of collecting dietary data. The repeated $24-\mathrm{h}$ recall method has a high reliability and validity, and, although not perfect, it is a dependable method for estimating the usual nutritional intake of a person and for relative comparisons (8).

Reviews of the literature $(4,15)$ indicate that shift work affects the frequency and temporal position of meals but not the total amounts of energy and nutrients ingested per se. As far as we know, analyses of the circadian distribution of energy have only been reported in one study (16), which showed that the distribution (but not total intake) varies as a function of work schedule. Since the dietary intake (amounts of energy and nutrients) and dietary composition (distribution between energy yielding macronutrients and nutrient density, respectively) in shift workers does not seem to differ from the diet of day workers or from that of the population in 
general (15), it must be concluded that the sleepwake cycle is a strong determinant for the circadian distribution of eating, but not for the total amounts consumed nor for the composition of the diet. Thus, if there really is a link between diet and cardiovascular disease among shift workers, it is probably related to chronometric aspects of eating.

As suggested in the introduction, one possible reason for the observed relation between night and morning eating and the cholesterol levels may be the changed phase relation of food intake and the circadian rhythmicity of digestive processes. Knowledge on the latter is rather limited (3), but circadian patterns have been observed for gastric emptying rate (17), hepatic enzyme activity (18), biliary excretion (18), anabolic and catabolic hormones (eg, insulin and cortisol), regulating tissue uptake, the synthesis of nutrients (5), and the like. This notion is also supported by the circadian variation of the pharmacokinetics and pharmacodynamics of drugs (19) and by the successful chronotherapy of diabetes mellitus (20).

With respect to the results of our study, it might be speculated that an early night meal stimulated lipogenic agents, such as insulin, at a time of day when their rhythms should be at their minimum values and, instead, the catabolic growth hormone should be released during sleep. It might also be speculated that an early morning meal might disturb the overall circadian rhythmicity of the anabolic and catabolic processes related to sleep and wakefulness. This phenomenon might, in turn, cause an imbalance in the endocrine rhythms associated with fat mobilization, and the imbalance would interfere with the successful mobilization of free fatty acids from fat depots (2). Admittedly, this is a highly tentative hypothesis that needs proper testing. Furthermore, the metabolic effects of eating during different times of the day might also be related to the circadian type of the persons (eg, morningness or eveningness) (5).

In this study, the best predictor of the lipids was total carbohydrates ingested during the night, but all other nutrients and energy showed significant correlations. They were also strongly intercorrelated. Thus it does not seem possible to identify any particular nutrient as the main "cause" of the increased levels or serum total cholesterol and LDL cholesterol. Rather, total intake at night seems implicated. This possibility is also in line with the observation of the positive correlation between the intake of fiber and lipids - the fiber parameters are, in this case, merely considered to represent total food intake.

If food intake on the night shift is related to increased serum lipid levels, one would expect shift workers to exhibit higher lipid levels than day workers. This was not the case, however (11). The reason for the lack of difference could have been the sample size. There are a couple of studies that exhibited higher serum cholesterol levels in three-shift workers $(21,22)$, as well as a few that did not (23-
25). However, no relationships were found between the reported higher levels of blood cholesterol in shift workers and dietary intake. One reason for this lack of a relationship might be that the 24-h intakes of energy and macronutrients were used for the correlations, while the distribution of intakes and time of day for consumption have not been considered (22, 24,25 ).

In conclusion, the main finding of this study of male three-shift workers was that the circadian distribution of energy was correlated with serum lipids, while the average daily consumption of energy and nutrients was not. It is suggested that the redistribution of food intake from diurnal eating to nocturnal eating is related to serum total cholesterol, LDL cholesterol, and HDL cholesterol, which might increase the risk for cardiovascular disease.

\section{Acknowledgments}

We would like to thank the following persons for making the study possible: the participants who gave their time, the management who supported the study, and Dr A Andersson, Ms I Carlsson, and Ms P Eriksson in the health care unit.

The studies were supported by grants from the Swedish Work Environment Fund and from Land \& Sjö-fonden; the studies were supported by technical assistance from the Swedish National Food Administration, Nutrition Division.

\section{References}

1. Tüchsen F. Working hours and ischaemic heart disease in Danish men: a 4-year cohort study of hospitalization. Int J Epidemiol 1993;22:215-21.

2. Armstrong $\mathrm{S}$. A chronometric approach to the study of feeding behaviour. Neurosci Behav Physiol 1980;4: $27-53$.

3. Halberg F. Some aspects of the chronobiology of nutrition: more work is needed on "when to eat". J Nutr 1989;119:333-43.

4. Tepas DI. Do eating and drinking habits interact with work schedule variables? Work Stress 1990;4:20311.

5. Minors DS, Waterhouse JM. Circadian rhythms and the human. Bristol: Wright PSG, 1981:332.

6. Åkerstedt T. Physiological and psychophysiological effects of shift work. Scand J Work Environ Health 1990;16 suppl 1:67-73.

7. Touitou Y, Haus E, editors. Biologic rhythms in clinical and laboratory medicine. Berlin: Springer-Verlag, 1992:730.

8. Gibson RS. Principles of nutritional assessment. Oxford: Oxford University Press, 1990:1—691.

9. Statens Livsmedelsverk [National Food Administration]. Vikttabeller för livsmedel och maträtter [Weight tables for foods and dishes]. Uppsala: Statens Livsmedelsverk, 1988.

10. National Food Administration. Food composition table - energy and nutrients. Uppsala: National Food Administration, 1993.

11. Lennernäs M, Hambræus L, Åkerstedt T. Nutrient intake in day and shift workers. Work Stress. In press.

12. Crowder MJ, Hand DJ. Analysis of repeated measures. Bury St Edmunds: ST Edmundsbury Press Ltd, 1990. 
Monographs on statistics and applied probability, no 41.

13. Cohen J. Multiple regression as a general data-analytic system. Psychol Bull 1968;70:426- 43.

14. Nordin M. MATs: a nutrient calculation system designed for research and education. Västerås: Rudans Lättdata, 1992.

15. Lennernäs M. Nutrition and shift work. The effect of work hours on dietary intake, meal patterns and nutritional status parameters [thesis]. Uppsala (Sweden): Uppsala University, 1993.

16. Lennernäs M A-C, Abrahamsson L, Hambræus L Åkerstedt T. The 24-hour intake of energy and nutrients in 3-shift workers. Ecol Food Nutr. In press.

17. Goo RH, Moore JG, Greenberg A, Alazraki NP. Circadian variations in gastric emptying of meals. Gastroenterology 1987;93:515-8.

18. Bélanger PM, Labrequw G. Biological rhythms in hepatic drug metabolism and biliary systems. In: Touitou Y, Haus E, editors. Biologic rhythms in clinical and laboratory medicine. Berlin: Springer Verlag, 1992: 403-9.

19. Bruguerolle B. Chronopharmacology. In: Touitou Y, Haus E, editors. Biological rhythms in clinical and laboratory medicine. Berlin: Springer-Verlag, 1992:
$114-50$.

20. Méjean L, Kolopp M, Drouin P. Chronobiology, nutrition, and diabetes mellitus. In: Touitou Y, Haus E, editors. Biological rhythms in clinical and laboratory medicine. Berlin: Springer-Verlag, 1992:375-85.

21. Thelle D, Forde O, Trygg K, Lehman EH. The Tromso heart study. Acta Med Scand 1976;200:107-18.

22. De Backer M, Kornitzer M, Dramix M, Peeters H, Kittel F. Irregular working hours and lipid levels in men. In: Schlierf G, Mörl $\mathrm{H}$, editors. Expanding horizons in atherosclerosis research. Berlin: Springer-Verlag, 1987:217-24.

23. Knutsson A, Åkerstedt $\mathrm{T}$, Jonsson $\mathrm{B}$, Orth-Gomer $\mathrm{K}$. Prevalence of risk factors for coronary heart disease among day and shift workers. Scand J Work Environ Health 1988; 14:317-21.

24. Knutsson A, Andersson H, Berglund U. Serum lipoproteins in day and shift workers: a prospective study. Br J Ind Med 1990;47:132-4.

25. Romon M, Nuttens $M-C$, Fievet $C$, Pot P, Bard JM, Furon D, et al. Increased triglyceride levels in shift workers. Am J Med 1992; 93:259—62.

Received for publication: 17 September 1993 